\title{
Evaluation of Clonal Variability in Shoot Coppicing Ability and in vitro Responses of Dalbergia sissoo Roxb.
}

\author{
By S. KALIA ${ }^{1,3}$, R. K. KALIA ${ }^{2}$ and S. K. SHARMA
}

Forest Research Institute, P.O I.P.E, Kaulagarh Road, Dehradun, (Uttaranchal)

(Received $17^{\text {th }}$ February 2004)

\begin{abstract}
Summary
Clonal variations were observed amongst 12 clones of Dalbergia sissoo belonging to four states (U.P, Uttaranchal, Haryana and Rajasthan) of India, representing four different geographical zones in respect of ex vitro shoot coppicing ability and in vitro responses. Coppicing ability of shoot hedges of clones exhibited significant variation which ranged from average of 13.81 coppiced shoots (Clone 40, Uttar Pradesh) to 9.29 (Clone 64, Haryana). Comparative analysis of clones from different regions in respect to their coppicing ability revealed that clones from U.P had higher coppicing ability whereas those from Haryana proved to be least coppicers. Regional variations were also exhibited in the in vitro multiple bud induction ability on nodal explants excised from shoot hedges of clones (mean number of buds induced and percentage of cultures forming multiple buds). Regional as well as inter clonal variations were recorded in the shoot proliferation efficiency as well as rootability of microshoots of these clones as well as their optimal plant growth regulator requirements. BAP alone $(2.5 \mu \mathrm{M})$ was sufficient for inducing multiple buds on cultured nodal explants of Uttaranchal and Uttar Pradesh region clones. On the contrary, clones from Rajasthan and Haryana had higher optimal requirement of $\mathrm{BAP}$ and in addition, they required media to be supplemented with auxin (NAA) for induction of multiple buds on explants. Correlation analysis between shoot coppicing ability of clones and in vitro performances of explants of these clones cultured on $2.5 \mu \mathrm{M}$ BAP indicates a positive correlation. Observation lays credence to our view that these characters are genetically controlled and shoot coppicing can be used as a marker character in optimizing in vitro performance of clones. Using the information generated by this paper in vitro production of elite planting material can be maximized by ameliorating plant growth regulator requirement in the medium.
\end{abstract}

Key words: Dalbergia sissoo, coppicing ability, clonal variation, in vitro, provenance, correlation, U.P. (Uttar Pradesh).

\section{Introduction}

Mass propagation of superior genotypes of tree species can be achieved by macropropagation and micropropagation. Development of suitable regeneration methodology for mass propagation (ex vitro and in vitro) applicable to entire population of species is limited by its genotypic diversity. Role of genotype during different phases of vegetative propagation has been elaborated by several workers (BROwN, 1981; HARTMAN and Kester, 1983; Panetsos et al., 1987; Haissig and RiemenSCHNEIDER, 1988; LEAKEY et al., 1994). Availability of cuttings for macropropagation from shoot hedges depends upon its coppicing magnitude, which is believed to be under genetic control

1) Uttaranchal College of Science and Technology, Dehradun, Uttaranchal, India.

$\left.{ }^{2}\right)$ Tissue Culture \& Cryopreservation Unit, National Bureau of Plant Genetic Resources, PUSA, New Delhi-110012.

${ }^{3}$ ) Address for correspondence: Dr. SANJAY KaLIA, 64, A.W.H.O, Indira Nagar, P.O New Forest, Dehradun, Uttaranchal, PIN-248006, India E-mail: sanjaykalia@hotmail.com
(GURUMURTHI, 2000). Variation in the coppicing ability amongst clones has been demonstrated in Dalbergia sissoo Roxb. (PAL et al., 2003) during macropropagation experiments.

Regeneration of any species under in vitro environment is the complicated interaction of genotype and available plant growth regulators in the medium. Maximizing the magnitude of response depends on the suitability of available plant growth regulator level, physiological and genotypic configuration of the explant (KALIA, 2003). Variability in the responses of clones and their reactivity to different steps of micropropagation (establishment, proliferation, rooting) has been demonstrated in Pinus radiata by HoRGAN (1987). In addition, AHUJA (1983), Coleman and ERNEST (1989) reported that shoot regeneration ability of different Populus clones (hardwood) is genotype dependent. Apart from shooting and rooting ability, differences in patterns of proliferation under in vitro environment have been reported in case of Eucalyptus hybrids (SHARMA and KALIA, 2004).

Dalbergia sissoo Roxb. (Leguminosae, Subfamily Papilionoideae) is a medium to large deciduous tree with a light crown. Sissoo is native to the foothills of the Himalayas of India, Pakistan and Nepal, which is its center of origin. It is primarily found growing naturally along river banks below 900 $\mathrm{m}$ elevation. Dalbergia sissoo is best known internationally as a premier timber species of the rosewood genus. Several reports document regeneration of the plantlets using various explants on different media and plant growth regulator combinations but each of these fail to throw light on clonal variations as well as upon the minimal physico chemical requirements for mass scale propagation (KALIA, 2003).

In the past decade resources of the tree have also dwindled because of die back of mature trees and indiscriminate felling due to human greed. The present work is an effort to investigate the extent of variability with respect to shoot coppicing ability and in vitro establishment of cultures amongst different clones of Dalbergia sissoo Roxb, exhibiting superior silvicultural traits from diverse geographical units (provenances). Study will help in standardization of physico-chemical conditions for in vitro propagation on mass scale through axillary bud proliferation.

\section{Materials and Methods}

\section{Plant material}

Plant material for the present experiment was collected from the vegetative multiplication garden (F.R. I.) where assemblage of clones raised by means of mature cuttings and cuttings from root suckers of selected plus trees were maintained as shoot hedges. Twelve clones were selected from this vegetative multiplication garden based on their performance in clonal trials at three different regions of India viz. Haryana (Bithmera), Punjab (Hoshiarpur), and Uttaranchal (Lal Kuan). This has generated the curiosity to investigate the ex vitro coppicing ability and in vitro proliferation pattern, multiplication rate and root- 
ing response of different clones growing in similar and diverse geographic locations in the country. Three clones each from Uttar Pradesh, Uttaranchal, Rajasthan and Haryana were chosen to study variation in above characters. These clones were selected based on the phenotypic scores of candidate plus trees viz. higher volume of wood, clean bole length and stem form etc. Geographical identity of these clones is detailed below:

\begin{tabular}{cc}
\hline Clone & Location and State \\
\hline 9 & Pathri, Uttaranchal \\
10 & Pathri, Uttaranchal \\
12 & Pathri, Uttaranchal \\
36 & Gonda, Uttar Pradesh \\
40 & Gonda, Uttar Pradesh \\
44 & Gonda, Uttar Pradesh \\
62 & Chichrauli, Haryana \\
64 & Chichrauli, Haryana \\
66 & Chichrauli, Haryana \\
88 & Hanumangarh, Rajasthan \\
90 & Hanumangarh, Rajasthan \\
101 & Hanumangarh, Rajasthan \\
\hline
\end{tabular}

\section{Ex vitro coppicing}

Coppicing ability was recorded for three consecutive years 2000-2002 in the above clones with stumps trimmed at $30 \mathrm{~cm}$ from the base. Data were collected for number of shoots proliferated in 40 (forty) shoot hedges of each clone during months of April and May.

\section{In vitro studies}

Surface sterilization:

Branches measuring 5 to $10 \mathrm{~cm}$ taken from shoot hedges were washed with running tap water and cut into nodal explants of 1.5-2.0 cm size. Explants were washed in liquid detergent solution (teepol, 4-5 drops/100 $\mathrm{ml}$ of double distilled water) for 10-15 minutes followed by two to three washes with double distilled water. Explants were then surface sterilized with $0.10 \%$ mercuric chloride for 20 minutes followed by $\mathrm{EtOH}$ (90\%) for 5 minutes and then rinsed with sterilized double distilled water four to five times. Before inoculation, proximal and distal ends of explants were trimmed to remove dead tissue.

\section{a.) Establishment of cultures}

To adjudge the multiple bud induction and axillary shoot proliferation, surface sterilized explants $(1.5-2.0 \mathrm{~cm})$ from different clones were cultured on MS medium (MURASHIGE and SkooG, 1962) supplemented with plant growth regulators. Effect of cytokinin (BAP) alone was assessed at concentrations $2.5 \mu \mathrm{M}-12.5 \mu \mathrm{M}$. Combination of BAP $(2.5 \mu \mathrm{M}-5.0 \mu \mathrm{M})$ were tried along with NAA $(0 \mu \mathrm{M}, 0.50 \mu \mathrm{M}, 1.25 \mu \mathrm{M})$ in the second set of experiment. Data were recorded in respect to multiple bud induction (number of multiple buds, percentage of cultures responding, percentage of responding cultures forming multiple buds). Only those explants which formed 3 or more than three buds over and above the single preformed axillary bud were scored for multiple buds and average number of buds induced was calculated by subtracting existing axillary buds at the time of inoculation. For axillary shoot proliferation data were recorded in respect of number of axillary shoots/explant, conversion percentage of buds into shoots (total number of shoots/total number of buds $\mathrm{x}$ 100) and length of induced shoots. For each treatment of experiment 24 replicates or explants were maintained and each experiment was repeated four times.

\section{b.) Multiplication of cultures}

Established explants were reared for one subculture on MS basal medium for two weeks before multiplication. For shoot multiplication propagule of three shoot $(2-2.5 \mathrm{~cm})$ each were used. For culture multiplication, full strength MS medium was supplemented with $2.5 \mu \mathrm{M}$ BAP. Multiplication rate was recorded in respect to gain in number of shoots per subculture cycle (increase in number of shoots $=$ number of shoots-number of shoots cultured) and dividing the gain by number of shoots in a propagule (three shoots). Multiplication data were recorded after sixth subculture cycle (three weeks) for five consecutive subculture cycles. Twenty-four replicates of each clone were maintained for all subculture cycles.

\section{c.) Rooting of shoots}

Rooting ability of different clones was adjudged by culturing in vitro multiplied single shoots on MS medium supplemented with IBA $(2.5-10 \mu \mathrm{M})$. Before culturing on rooting medium, shoots were cultured for one week on basal medium. For rooting data were recorded after three weeks in respect of percentage of rooted shoots, average root length and number of roots induced per explant. Each experiment, was repeated three times and twenty-four replicates were maintained for each treatment.

All the media used during establishment, multiplication and rooting experiments were supplemented with sucrose $(3 \%)$ as carbon source and gelled with $0.8 \%$ agar-agar unless and otherwise stated. Prior to inoculation, media were sterilized in autoclave at 15-pound pressure for 20 minutes. All chemicals used in the experiment were of Qualigen, India and Sigma make.

\section{d.) Hardening and acclimatization of plantlets}

In vitro rooted shoots were transferred to wide mouth bottles containing half strength liquid MS medium without vitamins and supplemented with $1 \%$ sucrose. Cotton was used as support to keep shoots upright in the liquid medium during hardening. Plantlets were placed in this medium for 15-20 days. For acclimatization, these hardened plantlets were transferred to polybags containing sand, soil (top soil) and farmyard manure (well decomposed cow dung) in 1:1:1 ratio and were supplied with $1 / 4 \mathrm{x}$ MS medium without vitamins. Initially the plantlets were covered with perforated polybags to retain moisture and were kept in shade. After 1 week, the perforated polybags were removed for $1-2 \mathrm{~h}$ daily, gradually the time was increased to $5-6 \mathrm{~h}$ and then to $8-10 \mathrm{~h}$ daily. Finally, the polybags were permanently removed. After one month, the hardened and acclimatized plantlets were transferred to pots.

Univariate analysis of variance of data were done using SPSS 8.0 software. Post hoc analysis of data were performed by Scheffe's method. Data recorded for each of the experiment is presented as Mean \pm S.D in the tables.

\section{e.) Correlation analysis}

In order to find correlation between shoot coppicing ability of clones i.e. mean number of coppiced shoots and in vitro parameters (mean number of multiple buds, percentage of responsive cultures, percentage of cultures forming multiple buds, mean number of shoots and percentage of buds proliferated into shoots) experiments were carried out. In each experiment twelve shoot hedges of each clone were selected randomly and from each shoot hedge two explants were cultured. Shoot hedges were scored for mean number of coppiced shoots at the time of explant collection and was correlated with in vitro responses of cultured explants. Experiment was carried out on 
Table 1. - Shoot coppicing ability of clones of Dalbergia sissoo Roxb.

\begin{tabular}{|c|c|c|}
\hline Provenance (State) & Clone & $\begin{array}{c}\text { Mean no. of coppiced shoots } \pm \\
\text { S.D }\end{array}$ \\
\hline Pathri (Uttaranchal) & $\begin{array}{c}9 \\
10 \\
12 \\
\end{array}$ & $\begin{array}{l}10.90 \pm 0.51 \\
11.63 \pm 0.71 \\
13.16 \pm 0.54\end{array}$ \\
\hline Gonda (Uttar Pradesh) & $\begin{array}{l}36 \\
40 \\
44 \\
\end{array}$ & $\begin{array}{l}13.11 \pm 0.75 \\
13.81 \pm 1.15 \\
13.37 \pm 0.58 \\
\end{array}$ \\
\hline Chichrauli (Haryana) & $\begin{array}{l}62 \\
64 \\
66 \\
\end{array}$ & $\begin{array}{c}10.08 \pm 0.82 \\
9.29 \pm 0.79 \\
9.42 \pm 0.69\end{array}$ \\
\hline Hanumangarh (Rajasthan) & $\begin{array}{c}88 \\
90 \\
101\end{array}$ & $\begin{array}{c}9.83 \pm 0.66 \\
10.85 \pm 0.93 \\
10.76 \pm 0.70\end{array}$ \\
\hline CD at 0.05 & Fcalc. & df error \\
\hline $\begin{array}{cc}\text { Provenance } & 1.24 \\
\text { Clone } & 3.04 \\
\end{array}$ & $\begin{array}{l}1.91 \\
0.76\end{array}$ & $\begin{array}{l}24 \\
32 \\
\end{array}$ \\
\hline
\end{tabular}

BAP concentrations ranging from $2.5 \mu \mathrm{M}-12.5 \mu \mathrm{M}$. For each experiment same set of shoot hedges were used for each of the treatment. Each experiment was carried out three times. Correlation was calculated by Karl Pearsons method and data presented in table for r-value or coefficient of correlation. Correlation was calculated for each of the individual concentration of BAP as well as for the pooled data.

\section{Results \\ Ex vitro studies}

Table 1 depicts the number of shoots regenerated on shoot hedges of $D$. sissoo clones during months of April and May for three consecutive seasons. Data revealed significant differences in the mean number of coppiced shoots amongst the clones. Number of shoots ranged from 13.81 (clone 40) to 9.29 (clone 64). Mean number of coppiced shoots also varied significantly within different geographical units with clones from Gonda

Table 2. - Multiple bud induction efficiency of Dalbergia sissoo clones under the regime of BAP.

\begin{tabular}{|c|c|c|c|c|c|c|c|}
\hline \multirow{2}{*}{ Provenance } & \multirow{2}{*}{ Clone } & \multirow{2}{*}{ Parameter } & \multicolumn{5}{|c|}{ BAP } \\
\hline & & & $2.5 \mu \mathrm{M}$ & $5 \mu \mathrm{M}$ & $7.5 \mu \mathrm{M}$ & $10 \mu \mathrm{M}$ & $12.5 \mu \mathrm{M}$ \\
\hline \multirow{3}{*}{$\begin{array}{c}\text { Pathri } \\
\text { (Uttaranchal) }\end{array}$} & 9 & $\begin{array}{l}\text { Mean no. of buds } \\
\text { Response }(\%) \\
\text { Multiple buds (\%) }\end{array}$ & $\begin{array}{c}3.13 \pm 0.28 \\
88.54 \pm 15.73 \\
68.68 \pm 9.34 \\
\end{array}$ & $\begin{array}{c}2.88 \pm 0.33 \\
84.38 \pm 9.24 \\
64.78 \pm 12.03 \\
\end{array}$ & $\begin{array}{c}2.78 \pm 0.25 \\
82.29 \pm 10.96 \\
54.91 \pm 6.08 \\
\end{array}$ & $\begin{array}{c}2.40 \pm 0.54 \\
66.67 \pm 9.00 \\
45.27 \pm 3.75 \\
\end{array}$ & $\begin{array}{c}2.21 \pm 0.24 \\
54.25 \pm 12.03 \\
26.85 \pm 7.29 \\
\end{array}$ \\
\hline & 10 & $\begin{array}{l}\text { Mean no. of buds } \\
\text { Response }(\%) \\
\text { Multiple buds (\%) }\end{array}$ & $\begin{array}{c}2.97 \pm 0.17 \\
86.46 \pm 9.24 \\
73.61 \pm 3.23 \\
\end{array}$ & $\begin{array}{c}2.85 \pm 0.23 \\
81.25 \pm 7.22 \\
61.21 \pm 7.01 \\
\end{array}$ & $\begin{array}{c}2.74 \pm 0.11 \\
79.17 \pm 10.76 \\
55.51 \pm 5.18 \\
\end{array}$ & $\begin{array}{c}2.32 \pm 0.20 \\
71.88 \pm 12.44 \\
43.85 \pm 4.91 \\
\end{array}$ & $\begin{array}{c}2.32 \pm 0.21 \\
56.25 \pm 5.38 \\
22.22 \pm 6.04 \\
\end{array}$ \\
\hline & 12 & $\begin{array}{l}\text { Mean no. of buds } \\
\text { Response }(\%) \\
\text { Multiple buds (\%) }\end{array}$ & $\begin{array}{c}3.33 \pm 0.19 \\
90.63 \pm 8.59 \\
79.21 \pm 4.68 \\
\end{array}$ & $\begin{array}{c}2.80 \pm 0.15 \\
81.25 \pm 13.82 \\
57.88 \pm 2.53 \\
\end{array}$ & $\begin{array}{c}2.76 \pm 0.20 \\
72.92 \pm 7.98 \\
49.52 \pm 8.39 \\
\end{array}$ & $\begin{array}{c}2.73 \pm 0.20 \\
78.13 \pm 3.99 \\
27.97 \pm 1.52 \\
\end{array}$ & $\begin{array}{c}2.63 \pm 0.13 \\
71.88 \pm 4.01 \\
18.82 \pm 2.42 \\
\end{array}$ \\
\hline \multirow{3}{*}{$\begin{array}{l}\text { Gonda (Uttar } \\
\text { Pradesh) }\end{array}$} & 36 & $\begin{array}{l}\text { Mean no. of buds } \\
\text { Response (\%) } \\
\text { Multiple buds (\%) }\end{array}$ & $\begin{array}{c}3.44 \pm 0.26 \\
91.67 \pm 7.61 \\
81.00 \pm 9.00 \\
\end{array}$ & $\begin{array}{c}3.28 \pm 0.11 \\
87.50 \pm 9.00 \\
70.41 \pm 5.27 \\
\end{array}$ & $\begin{array}{c}3.11 \pm 0.19 \\
81.25 \pm 5.38 \\
55.02 \pm 5.12 \\
\end{array}$ & $\begin{array}{c}2.73 \pm 0.24 \\
69.80 \pm 6.25 \\
47.78 \pm 7.80 \\
\end{array}$ & $\begin{array}{c}2.61 \pm 0.12 \\
65.63 \pm 7.12 \\
25.51 \pm 5.28 \\
\end{array}$ \\
\hline & 40 & $\begin{array}{l}\text { Mean no. of buds } \\
\text { Response (\%) } \\
\text { Multiple buds (\%) }\end{array}$ & $\begin{array}{c}3.59 \pm 0.31 \\
90.63 \pm 7.12 \\
80.11 \pm 9.03\end{array}$ & $\begin{array}{c}3.05 \pm 0.19 \\
86.46 \pm 6.25 \\
67.38 \pm 4.74\end{array}$ & $\begin{array}{c}2.75 \pm 0.16 \\
82.29 \pm 7.12 \\
62.48 \pm 7.40\end{array}$ & $\begin{array}{c}2.57 \pm 0.36 \\
75.00 \pm 6.80 \\
50.76 \pm 13.33\end{array}$ & $\begin{array}{c}2.48 \pm 0.08 \\
67.71 \pm 8.59 \\
41.55 \pm 2.55\end{array}$ \\
\hline & 44 & $\begin{array}{l}\text { Mean no. of buds } \\
\text { Response (\%) } \\
\text { Multiple buds (\%) }\end{array}$ & $\begin{array}{c}3.40 \pm 0.34 \\
88.54 \pm 7.89 \\
80.30 \pm 6.81 \\
\end{array}$ & $\begin{array}{c}2.82 \pm 0.13 \\
89.58 \pm 7.22 \\
60.59 \pm 3.57 \\
\end{array}$ & $\begin{array}{c}2.83 \pm 0.14 \\
79.17 \pm 5.89 \\
61.77 \pm 6.63 \\
\end{array}$ & $\begin{array}{r}2.68 \pm 0.37 \\
75.00 \pm 9.62 \\
47.50 \pm 5.00 \\
\end{array}$ & $\begin{array}{c}2.67 \pm 0.26 \\
64.63 \pm 10.42 \\
34.61 \pm 10.91 \\
\end{array}$ \\
\hline \multirow{3}{*}{$\begin{array}{l}\text { Chichrauli } \\
\text { (Haryana) }\end{array}$} & 62 & $\begin{array}{l}\text { Mean no. of buds } \\
\text { Response (\%) } \\
\text { Multiple buds (\%) }\end{array}$ & $\begin{array}{c}2.71 \pm 0.22 \\
60.42 \pm 8.67 \\
39.12 \pm 15.95 \\
\end{array}$ & $\begin{array}{c}2.84 \pm 0.13 \\
79.17 \pm 14.43 \\
60.80 \pm 4.20 \\
\end{array}$ & $\begin{array}{c}2.79 \pm 0.07 \\
69.79 \pm 11.47 \\
49.56 \pm 5.54 \\
\end{array}$ & $\begin{array}{c}2.58 \pm 0.13 \\
65.63 \pm 7.12 \\
35.96 \pm 6.73 \\
\end{array}$ & $\begin{array}{c}2.38 \pm 0.20 \\
52.09 \pm 8.67 \\
29.10 \pm 9.23 \\
\end{array}$ \\
\hline & 64 & $\begin{array}{l}\text { Mean no. of buds } \\
\text { Response }(\%) \\
\text { Multiple buds (\%) }\end{array}$ & $\begin{array}{c}2.66 \pm 0.15 \\
54.17 \pm 10.76 \\
44.47 \pm 14.76 \\
\end{array}$ & $\begin{array}{c}2.88 \pm 0.31 \\
58.33 \pm 9.00 \\
60.64 \pm 14.95 \\
\end{array}$ & $\begin{array}{c}2.91 \pm 0.12 \\
72.92 \pm 12.50 \\
65.98 \pm 5.59 \\
\end{array}$ & $\begin{array}{c}2.47 \pm 0.11 \\
57.29 \pm 8.59 \\
39.69 \pm 4.51 \\
\end{array}$ & $\begin{array}{c}2.43 \pm 0.24 \\
44.79 \pm 9.24 \\
23.11 \pm 6.15 \\
\end{array}$ \\
\hline & 66 & $\begin{array}{l}\text { Mean no. of buds } \\
\text { Response }(\%) \\
\text { Multiple buds (\%) }\end{array}$ & $\begin{array}{c}2.76 \pm 0.22 \\
60.42 \pm 7.98 \\
52.01 \pm 8.70 \\
\end{array}$ & $\begin{array}{c}3.28 \pm 0.23 \\
75.00 \pm 3.40 \\
77.75 \pm 9.13 \\
\end{array}$ & $\begin{array}{c}2.84 \pm 0.27 \\
67.71 \pm 7.12 \\
57.35 \pm 7.83 \\
\end{array}$ & $\begin{array}{c}2.53 \pm 0.24 \\
59.37 \pm 8.59 \\
41.83 \pm 4.69 \\
\end{array}$ & $\begin{array}{c}2.44 \pm 0.21 \\
53.13 \pm 7.88 \\
31.98 \pm 5.45 \\
\end{array}$ \\
\hline \multirow{3}{*}{$\begin{array}{c}\text { Hanumangarh } \\
\text { (Rajasthan) }\end{array}$} & 88 & $\begin{array}{l}\text { Mean no. of buds } \\
\text { Response }(\%) \\
\text { Multiple buds (\%) }\end{array}$ & $\begin{array}{l}2.24 \pm 0.18 \\
63.54 \pm 9.24 \\
24.72 \pm 2.82 \\
\end{array}$ & $\begin{array}{c}2.48 \pm 0.31 \\
72.92 \pm 10.49 \\
37.38 \pm 4.82 \\
\end{array}$ & $\begin{array}{c}2.73 \pm 0.10 \\
79.17 \pm 14.44 \\
44.58 \pm 4.25 \\
\end{array}$ & $\begin{array}{c}2.76 \pm 0.19 \\
88.54 \pm 3.99 \\
46.05 \pm 7.07 \\
\end{array}$ & $\begin{array}{c}2.46 \pm 0.17 \\
77.09 \pm 2.41 \\
33.77 \pm 10.76 \\
\end{array}$ \\
\hline & 90 & $\begin{array}{l}\text { Mean no. of buds } \\
\text { Response }(\%) \\
\text { Multiple buds }(\%)\end{array}$ & $\begin{array}{l}2.04 \pm 0.11 \\
68.75 \pm 9.92 \\
24.63 \pm 3.57 \\
\end{array}$ & $\begin{array}{c}2.37 \pm 0.19 \\
75.00 \pm 5.99 \\
39.13 \pm 15.35 \\
\end{array}$ & $\begin{array}{c}2.70 \pm 0.13 \\
89.59 \pm 4.17 \\
51.14 \pm 4.36 \\
\end{array}$ & $\begin{array}{c}2.49 \pm 0.28 \\
75.00 \pm 3.40 \\
40.11 \pm 6.85 \\
\end{array}$ & $\begin{array}{c}2.27 \pm 0.13 \\
72.92 \pm 7.98 \\
27.12 \pm 4.24 \\
\end{array}$ \\
\hline & 101 & $\begin{array}{l}\text { Mean no. of buds } \\
\text { Response }(\%) \\
\text { Multiple buds (\%) }\end{array}$ & $\begin{array}{c}2.42 \pm 0.09 \\
71.88 \pm 11.47 \\
33.23 \pm 4.60 \\
\end{array}$ & $\begin{array}{c}2.71 \pm 0.21 \\
79.17 \pm 14.43 \\
47.92 \pm 6.16 \\
\end{array}$ & $\begin{array}{c}2.93 \pm 0.16 \\
81.25 \pm 10.48 \\
55.34 \pm 16.30 \\
\end{array}$ & $\begin{array}{c}2.55 \pm 0.37 \\
82.29 \pm 5.24 \\
39.33 \pm 6.48 \\
\end{array}$ & $\begin{array}{c}2.38 \pm 0.15 \\
79.17 \pm 5.89 \\
29.87 \pm 8.65 \\
\end{array}$ \\
\hline Factor & & \multicolumn{2}{|c|}{ Variable } & \multicolumn{2}{|c|}{$\mathrm{CD}$ at 0.05} & $F$ calc. & df error \\
\hline \multicolumn{2}{|c|}{ Provenance } & \multicolumn{2}{|c|}{$\begin{array}{c}\text { Mean no of buds } \\
\text { Response }(\%) \\
\text { Multiple buds (\%) }\end{array}$} & \multicolumn{2}{|r|}{$\begin{array}{l}0.18 \\
6.10 \\
8.64\end{array}$} & $\begin{array}{l}15.85 \\
28.69 \\
12.37\end{array}$ & 236 \\
\hline \multicolumn{2}{|l|}{ Clone } & \multicolumn{2}{|c|}{$\begin{array}{c}\text { Mean no of buds } \\
\text { Response (\%) } \\
\text { Multiple buds (\%) }\end{array}$} & & $\begin{array}{c}0.48 \\
16.83 \\
23.74\end{array}$ & $\begin{array}{l}5.39 \\
8.28 \\
4.05\end{array}$ & 228 \\
\hline
\end{tabular}


Table 3. - Efficacy of BAP-NAA interaction in inducing multiple buds on nodal explants of Dalbergia sissoo clones.

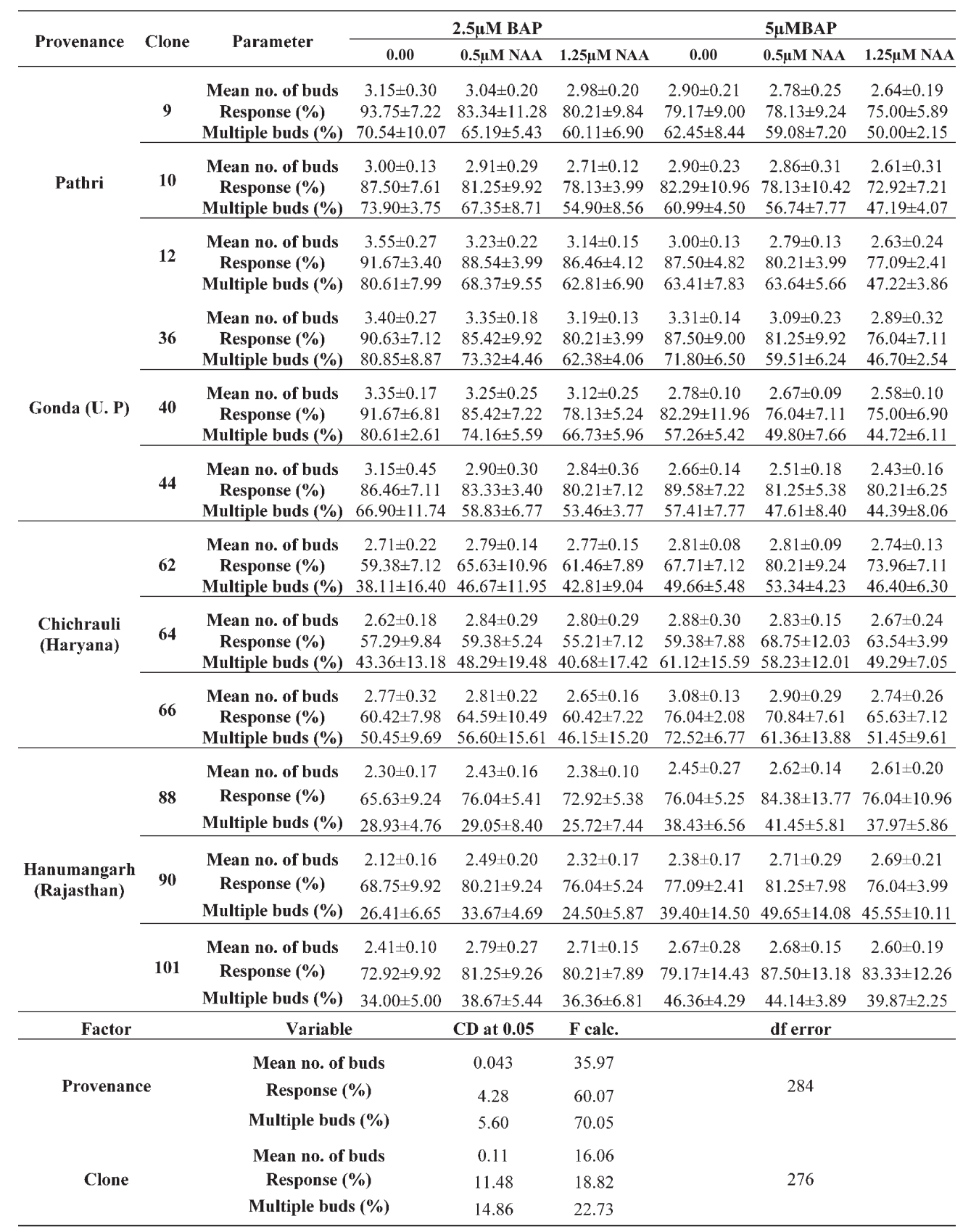

(Uttar Pradesh) being the highest coppicers and clones from Chichrauli (Haryana) the least coppicers.

\section{In vitro studies}

Successful establishment of aseptic cultures using nodal explants was achieved following the afore-mentioned surface sterilization procedure. Percentage establishment of aseptic culture varied amongst different clones from $95.83 \%$ to $100 \%$. No significant differences were noted amongst different clones in respect to aseptic culture establishment from explants collected from April to June.

\section{a.) Establishment of cultures}

\section{Multiple bud induction:}

Results indicated differential response of explants from different clones with varying BAP concentration in the medium (Table 2). Optimal concentration of BAP in inducing multiple buds on explants, their responsiveness and percentage of responsive culture inducing multiple buds varied from $2.5 \mu \mathrm{M}$ to $10 \mu \mathrm{M}$ amongst clones. Nodal explants of clones from Pathri and Gonda induced highest percentage of cultures with multiple bud on medium supplemented with $2.5 \mu \mathrm{M}$ BAP. Explants from only one clone (clone 88 ) required higher BAP supplemented medium $(10 \mu \mathrm{M})$ for their response optima (percentage of multiple buds induced). A similar trend was exhibited in respect of mean/average number of buds induced amongst the clones. Apart from exhibiting variation in their optimal requirement of BAP, explants from different clones exhibited variation amongst themselves in average number of buds induced, responsiveness as well as percentage of multiple buds induced. Clone 36 excelled over other clones in the percentage responsiveness, percentage of cultures inducing multiple buds as well as mean number of buds induced. Nodal explants from clones 88 and 90 exhibited least multiple bud induction poten- 
tial. Responsiveness of explants from Haryana clones (62, 64, 66) was lower than clones from other areas at their optimal concentration. Significant variations were observed amongst different provenances in respect to the parameters studied. Provenance Gonda proved superior for average number of multiple buds induced and frequency of multiple bud induction followed by Pathri, Chichrauli and Hanumangarh. However, percentage of responsive explants was highest in clones from Gonda and least in those from Chichrauli. Cultured explants of clones exhibited varying degree of callogenesis at distal end of explant in contact with the medium, which enhanced with increase in BAP concentration. Clones from Rajasthan and Haryana exhibited lesser callusing compared to clones from other states.

Addition of auxin (NAA) along with BAP resulted in enhanced responsiveness of explants from clones of Rajasthan $(88,90,101)$ and Haryana $(62,64,66)$ with respect to buds induced, percentage responsiveness as well as percentage of explants forming multiple buds. On the contrary, media combination of BAP and NAA was found deleterious for all parame- ters studied for multiple bud induction on explants of clones from Uttranchal $(9,10,12)$ and Uttar Pradesh (36, 40, 44). NAA $(0.5 \mu \mathrm{M})$ in combination with BAP exhibited promotery effect for all clones from Haryana and clone 90 and 101 from Rajasthan (Table 3). Multiple bud induction ability of clones declined when NAA concentration in the medium was increased to $1.25 \mu \mathrm{M}$, except in clone 88 from Rajasthan.

\section{Axillary shoot proliferation}

Variations were also registered amongst explants from clones for average number of axillary shoots proliferated and conversion percentage of buds into shoots. Nodal explants of clone 36 cultured on medium supplemented with $2.5 \mu \mathrm{M}$ BAP induced more mean number of shoots (3.21) and bud to shoot conversion percentage $(93.65 \%)$ compared to other clones, thus indicating their high shoot proliferation efficiency. A general trend of decreased bud conversion into shoots as well as shoot length was exhibited at concentrations beyond $5 \mu \mathrm{M}$ for all the clones except clone 88, which exhibited maximum bud to shoot conversion at $10 \mu \mathrm{M}$ BAP concentration (Table 4). No significant

Table 4. - Variation in axillary shoot proliferation potential of nodal explants of Dalbergia sissoo clones cultured on BAP supplemented media.

\begin{tabular}{|c|c|c|c|c|c|c|c|}
\hline \multirow{2}{*}{ Provenance } & \multirow{2}{*}{ Clone } & \multirow{2}{*}{ Parameter } & \multicolumn{5}{|c|}{ BAP } \\
\hline & & & $2.5 \mu \mathrm{M}$ & $5 \mu \mathrm{M}$ & $7.5 \mu \mathrm{M}$ & $10 \mu \mathrm{M}$ & $12.5 \mu \mathrm{M}$ \\
\hline \multirow{3}{*}{$\begin{array}{c}\text { Pathri } \\
\text { (Uttaranchal) }\end{array}$} & 9 & $\begin{array}{l}\text { Mean no. of shoots } \\
\text { Buds proliferated (\%) } \\
\text { Mean shoot length }\end{array}$ & $\begin{array}{c}2.53 \pm 0.26 \\
80.88 \pm 5.52 \\
1.45 \pm 0.17 \\
\end{array}$ & $\begin{array}{c}2.26 \pm 0.19 \\
79.01 \pm 7.65 \\
1.35 \pm 0.06 \\
\end{array}$ & $\begin{array}{c}1.95 \pm 0.22 \\
69.97 \pm 3.33 \\
1.05 \pm 0.08 \\
\end{array}$ & $\begin{array}{c}1.54 \pm 0.30 \\
64.64 \pm 2.68 \\
0.87 \pm 0.04 \\
\end{array}$ & $\begin{array}{c}1.36 \pm 0.13 \\
62.10 \pm 7.12 \\
0.86 \pm 0.16 \\
\end{array}$ \\
\hline & 10 & $\begin{array}{l}\text { Mean no. of shoots } \\
\text { Buds proliferated (\%) } \\
\text { Mean shoot length }\end{array}$ & $\begin{array}{c}2.07 \pm 0.15 \\
69.78 \pm 2.86 \\
1.38 \pm 0.07 \\
\end{array}$ & $\begin{array}{c}2.04 \pm 0.38 \\
71.08 \pm 8.54 \\
1.29 \pm 0.04 \\
\end{array}$ & $\begin{array}{c}1.82 \pm 0.31 \\
66.59 \pm 9.85 \\
1.13 \pm 0.06 \\
\end{array}$ & $\begin{array}{c}1.54 \pm 0.04 \\
66.71 \pm 7.71 \\
0.97 \pm 0.04 \\
\end{array}$ & $\begin{array}{c}1.25 \pm 0.44 \\
53.26 \pm 14.14 \\
0.78 \pm 0.15\end{array}$ \\
\hline & 12 & $\begin{array}{l}\text { Mean no. of shoots } \\
\text { Buds proliferated (\%) } \\
\text { Mean shoot length }\end{array}$ & $\begin{array}{c}2.92 \pm 0.31 \\
87.74 \pm 4.76 \\
1.36 \pm 0.07 \\
\end{array}$ & $\begin{array}{c}2.12 \pm 0.12 \\
75.95 \pm 3.90 \\
1.30 \pm 0.02 \\
\end{array}$ & $\begin{array}{c}2.27 \pm 0.12 \\
82.80 \pm 7.33 \\
1.12 \pm 0.06 \\
\end{array}$ & $\begin{array}{c}2.00 \pm 0.17 \\
74.27 \pm 3.18 \\
1.01 \pm 0.08 \\
\end{array}$ & $\begin{array}{c}1.20 \pm 0.18 \\
49.49 \pm 7.14 \\
0.81 \pm 0.13 \\
\end{array}$ \\
\hline \multirow{3}{*}{ Gonda (U. P) } & 36 & $\begin{array}{l}\text { Mean no. of shoots } \\
\text { Buds proliferated (\%) } \\
\text { Mean shoot length }\end{array}$ & $\begin{array}{c}3.21 \pm 0.15 \\
93.65 \pm 4.73 \\
1.74 \pm 0.10 \\
\end{array}$ & $\begin{array}{c}2.68 \pm 0.29 \\
81.58 \pm 8.20 \\
1.40 \pm 0.05 \\
\end{array}$ & $\begin{array}{c}2.15 \pm 0.19 \\
68.96 \pm 2.30 \\
1.25 \pm 0.09 \\
\end{array}$ & $\begin{array}{c}1.68 \pm 0.12 \\
61.66 \pm 6.38 \\
1.12 \pm 0.04 \\
\end{array}$ & $\begin{array}{c}1.31 \pm 0.19 \\
49.74 \pm 5.22 \\
1.11 \pm 0.14 \\
\end{array}$ \\
\hline & 40 & $\begin{array}{l}\text { Mean no. of shoots } \\
\text { Buds proliferated (\%) } \\
\text { Mean shoot length }\end{array}$ & $\begin{array}{c}3.07 \pm 0.31 \\
85.66 \pm 2.88 \\
1.58 \pm 0.09 \\
\end{array}$ & $\begin{array}{c}2.60 \pm 0.18 \\
85.11 \pm 2.90 \\
1.45 \pm 0.11 \\
\end{array}$ & $\begin{array}{c}2.18 \pm 0.15 \\
79.51 \pm 6.14 \\
1.30 \pm 0.13 \\
\end{array}$ & $\begin{array}{c}1.64 \pm 0.10 \\
64.68 \pm 7.63 \\
1.15 \pm 0.07 \\
\end{array}$ & $\begin{array}{c}1.54 \pm 0.20 \\
62.19 \pm 9.23 \\
1.06 \pm 0.08 \\
\end{array}$ \\
\hline & 44 & $\begin{array}{l}\text { Mean no. of shoots } \\
\text { Buds proliferated (\%) } \\
\text { Mean shoot length }\end{array}$ & $\begin{array}{c}2.87 \pm 0.45 \\
84.17 \pm 5.41 \\
1.47 \pm 0.11 \\
\end{array}$ & $\begin{array}{c}2.02 \pm 0.26 \\
71.72 \pm 9.04 \\
1.39 \pm 0.05 \\
\end{array}$ & $\begin{array}{c}2.24 \pm 0.24 \\
79.03 \pm 8.20 \\
1.19 \pm 0.07 \\
\end{array}$ & $\begin{array}{c}1.71 \pm 0.16 \\
64.09 \pm 3.75 \\
1.10 \pm 0.13 \\
\end{array}$ & $\begin{array}{c}1.36 \pm 0.20 \\
50.85 \pm 5.96 \\
1.01 \pm 0.18 \\
\end{array}$ \\
\hline \multirow{3}{*}{$\begin{array}{l}\text { Chichrauli } \\
\text { (Haryana) }\end{array}$} & 62 & $\begin{array}{l}\text { Mean no. of shoots } \\
\text { Buds proliferated (\%) } \\
\text { Mean shoot length }\end{array}$ & $\begin{array}{c}2.07 \pm 0.35 \\
76.32 \pm 9.90 \\
1.21 \pm 0.05 \\
\end{array}$ & $\begin{array}{c}2.47 \pm 0.21 \\
87.20 \pm 5.05 \\
1.25 \pm 0.09 \\
\end{array}$ & $\begin{array}{c}2.26 \pm 0.28 \\
80.74 \pm 8.35 \\
1.09 \pm 0.11 \\
\end{array}$ & $\begin{array}{c}1.69 \pm 0.17 \\
65.73 \pm 8.85 \\
0.86 \pm 0.08 \\
\end{array}$ & $\begin{array}{c}1.49 \pm 0.34 \\
58.42 \pm 10.40 \\
0.75 \pm 0.09 \\
\end{array}$ \\
\hline & 64 & $\begin{array}{l}\text { Mean no. of shoots } \\
\text { Buds proliferated (\%) } \\
\text { Mean shoot length }\end{array}$ & $\begin{array}{c}2.12 \pm 0.24 \\
79.54 \pm 4.48 \\
1.31 \pm 0.07 \\
\end{array}$ & $\begin{array}{c}2.33 \pm 0.34 \\
80.56 \pm 4.23 \\
1.22 \pm 0.10 \\
\end{array}$ & $\begin{array}{c}2.35 \pm 0.18 \\
80.57 \pm 3.62 \\
1.10 \pm 0.12 \\
\end{array}$ & $\begin{array}{c}1.87 \pm 0.14 \\
75.61 \pm 4.35 \\
1.10 \pm 0.12 \\
\end{array}$ & $\begin{array}{c}1.60 \pm 0.22 \\
60.32 \pm 9.98 \\
0.91 \pm 0.10\end{array}$ \\
\hline & 66 & $\begin{array}{l}\text { Mean no. of shoots } \\
\text { Buds proliferated }(\%) \\
\text { Mean shoot length }\end{array}$ & $\begin{array}{c}2.46 \pm 0.28 \\
89.00 \pm 8.01 \\
1.37 \pm 0.08\end{array}$ & $\begin{array}{c}2.98 \pm 0.31 \\
90.57 \pm 3.60 \\
1.29 \pm 0.09\end{array}$ & $\begin{array}{c}2.50 \pm 0.42 \\
87.48 \pm 8.94 \\
1.12 \pm 0.11\end{array}$ & $\begin{array}{c}1.94 \pm 0.35 \\
76.35 \pm 8.91 \\
0.83 \pm 0.10\end{array}$ & $\begin{array}{c}1.67 \pm 0.24 \\
60.36 \pm 6.55 \\
1.06 \pm 0.18\end{array}$ \\
\hline \multirow{3}{*}{$\begin{array}{c}\text { Hanumangarh } \\
\text { (Rajasthan) }\end{array}$} & 88 & $\begin{array}{l}\text { Mean no. of shoots } \\
\text { Buds proliferated } \\
\text { Mean shoot length }\end{array}$ & $\begin{array}{c}1.60 \pm 0.23 \\
71.43 \pm 7.01 \\
1.26 \pm 0.05 \\
\end{array}$ & $\begin{array}{c}1.81 \pm 0.12 \\
73.66 \pm 7.03 \\
1.22 \pm 0.09 \\
\end{array}$ & $\begin{array}{c}2.13 \pm 0.30 \\
77.92 \pm 11.95 \\
1.30 \pm 0.04 \\
\end{array}$ & $\begin{array}{c}2.22 \pm 0.07 \\
80.83 \pm 3.91 \\
1.28 \pm 0.06 \\
\end{array}$ & $\begin{array}{c}1.62 \pm 0.14 \\
66.04 \pm 3.89 \\
1.12 \pm 0.03 \\
\end{array}$ \\
\hline & 90 & $\begin{array}{l}\text { Mean no. of shoots } \\
\text { Buds proliferated (\%) } \\
\text { Mean shoot length }\end{array}$ & $\begin{array}{c}1.60 \pm 0.14 \\
78.54 \pm 7.58 \\
1.29 \pm 0.07 \\
\end{array}$ & $\begin{array}{c}1.93 \pm 0.05 \\
81.97 \pm 6.94 \\
1.30 \pm 0.08 \\
\end{array}$ & $\begin{array}{c}2.14 \pm 0.26 \\
78.92 \pm 6.64 \\
1.32 \pm 0.09 \\
\end{array}$ & $\begin{array}{c}1.91 \pm 0.20 \\
76.64 \pm 2.97 \\
1.23 \pm 0.06 \\
\end{array}$ & $\begin{array}{c}1.55 \pm 0.06 \\
64.36 \pm 4.30 \\
1.07 \pm 0.08 \\
\end{array}$ \\
\hline & 101 & $\begin{array}{l}\text { Mean no. of shoots } \\
\text { Buds proliferated }(\%) \\
\text { Mean shoot length }\end{array}$ & $\begin{array}{c}1.75 \pm 0.36 \\
72.17 \pm 12.10 \\
1.34 \pm 0.11 \\
\end{array}$ & $\begin{array}{c}2.26 \pm 0.14 \\
84.25 \pm 10.39 \\
1.18 \pm 0.10 \\
\end{array}$ & $\begin{array}{c}2.43 \pm 0.19 \\
82.73 \pm 3.39 \\
1.33 \pm 0.04 \\
\end{array}$ & $\begin{array}{c}2.17 \pm 0.21 \\
85.35 \pm 5.60 \\
1.27 \pm 0.09 \\
\end{array}$ & $\begin{array}{c}1.77 \pm 0.16 \\
74.48 \pm 6.84 \\
0.88 \pm 0.07 \\
\end{array}$ \\
\hline \multicolumn{2}{|l|}{ Factor } & Variable & \multicolumn{2}{|c|}{ CD at 0.05} & calc. & \multicolumn{2}{|c|}{ df error } \\
\hline \multicolumn{2}{|c|}{ Provenance } & $\begin{array}{c}\text { Mean no. of shoots } \\
\text { Buds proliferated (\%) } \\
\text { Mean shoot length (\%) }\end{array}$ & $\begin{array}{c}0.26 \\
5.93 \\
0.105\end{array}$ & & $\begin{array}{l}3.55 \\
5.98 \\
15.04\end{array}$ & \multicolumn{2}{|c|}{236} \\
\hline \multicolumn{2}{|l|}{ Clone } & $\begin{array}{c}\text { Mean no. of shoots } \\
\text { Buds proliferated (\%) } \\
\text { Mean shoot length (\%) }\end{array}$ & $\begin{array}{c}0.69 \\
16.01 \\
0.29\end{array}$ & & $\begin{array}{l}2.29 \\
3.19 \\
4.36\end{array}$ & \multicolumn{2}{|c|}{228} \\
\hline
\end{tabular}


Table 5. - Effect of BAP-NAA interaction on axillary shoot proliferation on nodal explants of Dalbergia sissoo clones.

\begin{tabular}{|c|c|c|c|c|c|c|c|c|}
\hline \multirow{2}{*}{ Provenance } & \multirow{2}{*}{ Clone } & \multirow{2}{*}{ Parameter } & \multicolumn{3}{|c|}{$2.5 \mu \mathrm{M}$ BAP } & \multicolumn{3}{|c|}{$5 \mu \mathrm{MBAP}$} \\
\hline & & & 0.00 & $0.5 \mu \mathrm{M}$ NAA & $1.25 \mu \mathrm{M}$ NAA & 0.00 & $0.5 \mu \mathrm{M}$ NAA & $1.25 \mu \mathrm{M}$ NAA \\
\hline \multirow{9}{*}{$\begin{array}{c}\text { Pathri } \\
\text { (Uttaranchal) }\end{array}$} & \multirow{3}{*}{9} & Mean no. of shoots & $2.54 \pm 0.25$ & $2.27 \pm 0.22$ & $2.14 \pm 0.18$ & $2.17 \pm 0.13$ & $1.95 \pm 0.23$ & $1.70 \pm 0.13$ \\
\hline & & Buds proliferated (\%) & $80.82 \pm 5.62$ & $74.58 \pm 4.10$ & $71.54 \pm 1.50$ & $75.00 \pm 2.45$ & $70.07 \pm 3.51$ & $64.65 \pm 2.78$ \\
\hline & & Mean shoot length & $1.39 \pm 0.10$ & $1.33 \pm 0.14$ & $1.21 \pm 0.06$ & $1.34 \pm 0.06$ & $1.12 \pm 0.05$ & $1.06 \pm 0.08$ \\
\hline & \multirow{3}{*}{10} & Mean no. of shoots & $2.38 \pm 0.11$ & $2.12 \pm 0.28$ & $1.81 \pm 0.17$ & $2.06 \pm 0.33$ & $1.90 \pm 0.47$ & $1.72 \pm 0.50$ \\
\hline & & iferated (\%) & $79.32 \pm 4.52$ & $72.79 \pm$ & 66.70 & $70.92 \pm 8.10$ & $66.11 \pm 13.53$ & $65.18 \pm 12.49$ \\
\hline & & $\mathbf{M e}$ & $1.33 \pm 0.09$ & $1.24 \pm 0.12$ & $1.07 \pm$ & $1.26 \pm 0.03$ & $1.13 \pm 0.14$ & $0.97 \pm 0.05$ \\
\hline & \multirow{3}{*}{12} & Mean no. of shoots & $3.09 \pm 0.21$ & $2.74 \pm 0.29$ & $2.39 \pm 0.13$ & $2.60 \pm 0.20$ & $2.17 \pm 0.14$ & $1.88 \pm 0.14$ \\
\hline & & Buds proliferated (\%) & $87.22 \pm 3.78$ & $84.89 \pm 3.59$ & $76.13 \pm 4.38$ & $86.60 \pm 4.50$ & $77.63 \pm 5.10$ & $72.10 \pm 9.27$ \\
\hline & & Mean shoot length & $1.42 \pm 0.09$ & $1.26 \pm 0.04$ & $1.13 \pm 0.04$ & $1.35 \pm 0.06$ & $1.20 \pm 0.11$ & $1.02 \pm 0.07$ \\
\hline \multirow{9}{*}{ Gonda (U P) } & \multirow{3}{*}{36} & Mean no. of shoots & $3.22 \pm 0.16$ & $2.79 \pm 0.19$ & $2.38 \pm 0.10$ & $2.68 \pm 0.29$ & $2.19 \pm 0.55$ & $1.90 \pm 0.45$ \\
\hline & & Buds proliferated (\%) & $94.89 \pm 4.57$ & $83.36 \pm 5.38$ & $74.73 \pm 2.13$ & $80.83 \pm 6.77$ & $70.55 \pm 12.81$ & $66.07 \pm 15.04$ \\
\hline & & Mean shoot length & $1.63 \pm 0.12$ & $1.33 \pm 0.08$ & $1.16 \pm 0.09$ & $1.42 \pm 0.09$ & $1.24 \pm 0.17$ & $1.09 \pm 0.10$ \\
\hline & \multirow{3}{*}{40} & Mean no. of shoots & $2.85 \pm 0.28$ & $2.65 \pm 0.42$ & $2.34 \pm 0.23$ & $2.06 \pm 0.11$ & $1.86 \pm 0.20$ & $1.72 \pm 0.09$ \\
\hline & & Buds proliferated $(\%)$ & $84.92 \pm 4.18$ & $81.36 \pm 6.67$ & $75.04 \pm 2.79$ & $74.14 \pm 4.94$ & $69.68 \pm 5.75$ & $66.68 \pm 1.86$ \\
\hline & & Mean shoot length & $1.49 \pm 0.11$ & $1.22 \pm 0.04$ & $0.97 \pm 0.13$ & $1.39 \pm 0.06$ & $1.16 \pm 0.09$ & $0.85 \pm 0.08$ \\
\hline & \multirow{3}{*}{44} & Mean no. of shoots & $2.56 \pm 0.48$ & $2.25 \pm 0.06$ & $1.98 \pm 0.13$ & $1.86 \pm 0.32$ & $1.52 \pm 0.21$ & $1.42 \pm 0.14$ \\
\hline & & Buds proliferated (\%) & $80.98 \pm 5.20$ & $78.19 \pm 7.90$ & $70.77 \pm 10.94$ & $69.82 \pm 9.78$ & $60.53 \pm 7.30$ & $58.41 \pm 5.54$ \\
\hline & & Mean shoot length & $1.42 \pm 0.09$ & $1.16 \pm 0.15$ & $1.01 \pm 0.04$ & $1.35 \pm 0.11$ & $1.15 \pm 0.08$ & $0.93 \pm 0.16$ \\
\hline \multirow{9}{*}{$\begin{array}{l}\text { Chichrauli } \\
\text { (Haryana) }\end{array}$} & \multirow{3}{*}{62} & Mean no. of shoots & $1.95 \pm 0.31$ & $2.27 \pm 0.27$ & $2.08 \pm 0.17$ & $2.28 \pm 0.23$ & $2.21 \pm 0.18$ & $1.90 \pm 0.22$ \\
\hline & & Buds proliferated (\%) & $71.81 \pm 8.52$ & $81.23 \pm 7.72$ & $75.49 \pm 6.69$ & $80.94 \pm 7.06$ & $78.74 \pm 7.52$ & $69.19 \pm 7.17$ \\
\hline & & Mean shoot length & $1.23 \pm 0.05$ & $1.12 \pm 0.11$ & $0.98 \pm 0.06$ & $1.26 \pm 0.10$ & $1.03 \pm 0.13$ & $0.87 \pm 0.09$ \\
\hline & \multirow{3}{*}{64} & Mean no. of shoots & $2.12 \pm 0.15$ & $2.39 \pm 0.47$ & $2.09 \pm 0.34$ & $2.33 \pm 0.35$ & $2.18 \pm 0.18$ & $1.84 \pm 0.21$ \\
\hline & & Buds proliferated $(\%)$ & $80.71 \pm 3.07$ & $83.47 \pm 7.74$ & $74.46 \pm 7.26$ & $80.82 \pm 4.61$ & $77.09 \pm 4.78$ & $69.17 \pm 3.35$ \\
\hline & & Mean shoot length & $1.35 \pm 0.12$ & $1.18 \pm 0.06$ & $1.04 \pm 0.14$ & $1.26 \pm 0.09$ & $1.06 \pm 0.04$ & $1.03 \pm 0.06$ \\
\hline & \multirow{3}{*}{66} & Mean no. of shoots & $2.36 \pm 0.26$ & & $2.10 \pm 0.21$ & $2.72 \pm 0.24$ & & \\
\hline & & Buds proliferated $(\%)$ & $85.64 \pm 6.62$ & $86.35 \pm 7.81$ & $79.13 \pm 13.8$ & $88.05 \pm 5.87$ & $87.32 \pm 8.60$ & $78.78 \pm 6.38$ \\
\hline & & Mean shoot length & $1.41 \pm 0.09$ & $1.35 \pm 0.15$ & $1.17 \pm 0.08$ & $1.30 \pm 0.06$ & .06 & $1.09 \pm 0.12$ \\
\hline \multirow{9}{*}{$\begin{array}{l}\text { Hanumangarh } \\
\text { (Rajasthan) }\end{array}$} & \multirow{3}{*}{88} & Mean no. of shoots & $1.69 \pm 0.17$ & $1.86 \pm 0.23$ & $1.78 \pm 0.15$ & $1.81 \pm 0.13$ & $2.15 \pm 0.31$ & $2.11 \pm 0.41$ \\
\hline & & Buds proliferated & $73.25 \pm 5.97$ & $76.09 \pm 6.44$ & $74.70 \pm 5.62$ & $74.25 \pm 6.72$ & $82.23 \pm 11.70$ & $80.86 \pm 13.22$ \\
\hline & & Mean shoot length & $128 \pm 0.06$ & $128 \pm 0.07$ & $1.16 \pm 0.03$ & $1.25 \pm 0.07$ & $1.24 \pm 0.08$ & $1.08 \pm 0.11$ \\
\hline & \multirow{3}{*}{90} & Mean no. of shoots & $1.59 \pm 0.16$ & $1.98 \pm 0.11$ & $1.63 \pm 0.21$ & $1.95 \pm 0.04$ & $2.31 \pm 0.11$ & $2.21 \pm 0.16$ \\
\hline & & Buds proliferated (\%) & $75.24 \pm 5.18$ & $80.18 \pm 9.78$ & $70.95 \pm 12.63$ & $82.05 \pm 6.67$ & $85.76 \pm 5.58$ & $82.09 \pm 3.29$ \\
\hline & & Mean shoot length & $1.29 \pm 0.08$ & $1.30 \pm 0.04$ & $1.12 \pm 0.03$ & $1.28 \pm 0.11$ & $1.22 \pm 0.07$ & $1.09 \pm 0.06$ \\
\hline & \multirow{3}{*}{101} & Mean no. of shoots & $1.77 \pm 0.36$ & $2.05 \pm 0.27$ & $1.81 \pm 0.23$ & $2.15 \pm 0.17$ & $2.19 \pm 0.14$ & $2.08 \pm 0.12$ \\
\hline & & Buds proliferated (\%) & $73.49 \pm 13.87$ & $73.47 \pm 8.39$ & $66.49 \pm 7.60$ & $80.79 \pm 9.57$ & $82.13 \pm 9.76$ & $80.33 \pm 10.34$ \\
\hline & & Mean shoot length & $1.32 \pm 0.12$ & $1.35 \pm 0.03$ & $1.10 \pm 0.14$ & $1.219 \pm 0.08$ & $1.22 \pm 0.09$ & $1.03 \pm 0.06$ \\
\hline \multicolumn{2}{|l|}{ Factor } & Variable & & CD at 0. & & F calc. & df $\mathrm{e}$ & rror \\
\hline & & Mean no. of shoot & & 0.19 & & 7.84 & & \\
\hline Provenanc & & Buds proliferated ( & & 4.46 & & 4.50 & & 34 \\
\hline & & Mean shoot length ( & $(\%)$ & 0.08 & & 1.77 & & \\
\hline & & Mean no. of shoot & & 0.48 & & 7.94 & & \\
\hline Clone & & Buds proliferated ( & & 11.53 & & 5.23 & & 76 \\
\hline & & Mean shoot length ( & & 0.21 & & 3.02 & & \\
\hline
\end{tabular}

differences were recorded in average number of shoots proliferated in different clones, whereas bud to shoot conversion was highest in clone 66 and least in clone 10. Average shoot number also varied amongst clones from different states (provenances) with highest being in clones collected from Gonda (U.P) followed by clones from Chichrauli (Haryana), Hanumangarh (Rajasthan) and Pathri (Uttranchal). However, conversion of buds into shoots followed a different trend with highest in clones from Haryana and least in clones from Pathri.

A diminutive trend in average shoot number and bud conversion into shoots was observed in clones from Uttaranchal and Uttar Pradesh with increase in NAA concentration in the medium. Media supplemented with NAA $(0.5 \mu \mathrm{M})$ proved effective for axillary shoot proliferation and bud into shoot conversion in clones from Haryana and Rajasthan. Higher concentration of NAA $(1.25 \mu \mathrm{M})$ proved deleterious to clones irrespective of their place of origin (Table 5). Incorporation of NAA in the medium enhanced callusing at the base of explants.

\section{b.) Multiplication of cultures}

Differential in vitro responses of clones on media with varying plant growth regulator combinations suggested their differential reactivity towards plant growth regulators as well as elicited differences in their multiplication potential. Significant differences were observed amongst clones in respect of their multiplication potential. Multiplication potential of clone 44 was highest and clone 90 was least (1.78). Clones also exhibited significant regional variation in their multiplication rates (Table 6). Clones from Uttar Pradesh exhibited significantly higher multiplication ability than clones from Uttaranchal, Rajasthan and Haryana. Average shoot length, an index of shoot growth was significantly higher in clones from Rajasthan 
Table 6. - Shoot multiplication potential of Dalbergia sissoo clones cultured on MS medium supplemented with $2.5 \mu \mathrm{M}$ BAP.

\begin{tabular}{|c|c|c|c|c|}
\hline Clone & Increase in shoot number & Average shoot length & \multicolumn{2}{|c|}{ Multiplication rate } \\
\hline 9 & $7.14 \pm 0.64$ & $1.80 \pm 0.13$ & \multicolumn{2}{|c|}{2.38} \\
\hline 10 & $7.08 \pm 0.80$ & $2.13 \pm 0.11$ & \multicolumn{2}{|c|}{2.36} \\
\hline 12 & $9.66 \pm 1.17$ & $2.11 \pm 0.14$ & \multicolumn{2}{|c|}{3.22} \\
\hline 36 & $7.97 \pm 0.51$ & $2.24 \pm 0.22$ & \multicolumn{2}{|c|}{2.66} \\
\hline 40 & $8.36 \pm 0.98$ & $2.23 \pm 0.10$ & \multicolumn{2}{|c|}{2.79} \\
\hline 44 & $11.75 \pm 1.75$ & $2.34 \pm 0.05$ & \multicolumn{2}{|c|}{3.92} \\
\hline 62 & $6.97 \pm 0.50$ & $2.28 \pm 0.14$ & \multicolumn{2}{|c|}{2.32} \\
\hline 64 & $7.02 \pm 0.80$ & $2.59 \pm 0.07$ & \multicolumn{2}{|c|}{2.34} \\
\hline 66 & $6.30 \pm 0.79$ & $2.39 \pm 0.08$ & \multicolumn{2}{|c|}{2.10} \\
\hline 88 & $5.86 \pm 0.71$ & $2.38 \pm 0.14$ & \multicolumn{2}{|c|}{1.95} \\
\hline 90 & $5.33 \pm 0.38$ & $2.51 \pm 0.06$ & \multicolumn{2}{|c|}{1.78} \\
\hline 101 & $6.69 \pm 0.51$ & $2.44 \pm 0.12$ & \multicolumn{2}{|c|}{2.23} \\
\hline Factor & Variable & CD at 0.05 & F calc. & df error \\
\hline Provenance & $\begin{array}{l}\text { Increase in shoot number } \\
\text { Shoot length }\end{array}$ & $\begin{array}{l}1.458 \\
0.17\end{array}$ & $\begin{array}{l}17.14 \\
22.99\end{array}$ & 56 \\
\hline Clone & $\begin{array}{l}\text { Increase in shoot number } \\
\text { Shoot length }\end{array}$ & $\begin{array}{l}2.58 \\
0.37\end{array}$ & $\begin{array}{l}20.35 \\
14.20\end{array}$ & 48 \\
\hline
\end{tabular}

and Haryana than clones from Uttar Pradesh and Uttaranchal. Multiplied shoots of clone 64 were longest and clone 9 shortest. Significant differences were recorded for shoot length amongst clones.

\section{c.) Rooting of shoots}

Rooting percentage of microshoots of different clones differed significantly from each other (Table 7). Microshoots of clone 36 exhibited highest rooting percentage $(87.50 \%)$ while those of clone 101 exhibited least rooting at the optimal phytohormonal concentration. On the contrary, longest roots were induced on the microshoots of clone 101 than any other clone. Efficiency of rooting also varied with IBA concentration in the medium. Microshoots of clones 12 and 40 exhibited higher rooting percentages on media supplemented with $2.5 \mu \mathrm{M}$ IBA, whereas, for microshoots of clones $9,10,36,42,62,645 \mu \mathrm{M}$ IBA was optimal and those of clones 66, 80, 90 and clone 101 rooted at higher frequency on IBA concentration of $7.5 \mu \mathrm{M}$ and $10 \mu \mathrm{M}$ respectively. Significant differences were recorded amongst clones with respect to percentage of rooted microshoots, root length and root number. Clone 36 excelled in all the three parameters of study. Rooting parameters also varied significantly between different provenances with Gonda provenance excelling in all three parameters.

\section{d.) Hardening and acclimatization}

Rooted microshoots were successfully hardened. Plantlets after successful hardening were transferred to poly bags filled with different potting media. Potting media containing sand: soil: FYM (1:1:1) was found superior to other media. Percentage of plants successfully acclimatized varied with clones (Data not presented). Acclimatized plantlets were then successfully transferred to earthen pots and then to field.

\section{e.) Correlation analysis}

A significant and positive correlation was observed between the shoot coppicing ability and in vitro characters of cultured explants on the BAP concentration of $2.5 \mu \mathrm{M}$ except percentage of buds proliferated into shoots (Table 8). Level of correlation exhibited a decline with increasing BAP concentration in the medium.

\section{Discussion}

Genetic make up and growth environment of the donor plant explicits itself in its phenotypic expression. Therefore, clonal variation was evident in the shoot coppicing ability and in vitro responses of the different clones. Significant variations were observed in the shoot coppicing ability of different clones. Present finding is in agreement with those of PAL et al. (2003).

In vitro performance (multiple bud formation) and survival of cultures (percentage response) during establishment phase as well as plant growth regulator requirement varied considerably amongst different clones. Clones from Uttar Pradesh and Uttaranchal required 2.5 $\mu \mathrm{M}$ BAP alone. On the other hand clones selected from Rajasthan required media combination of BAP and NAA $(0.5 \mu \mathrm{M})$. Our results are in agreement with other reports where differential requirement of plant growth regulators and variability in responses was noted. HAMMERSCHLAG (1982) noted significant differences in survival response between cultivars of Prunus avium. Studies indicate that diverse cultivars have differential responses and growth requirements (NORTON and NorTON, 1985; SiMPson and BELL, 1989).

Shoot proliferation ability of different clones exhibited a variation amongst clones. A general trend of reduced proliferation with or conversion of buds into shoots was observed with increase in BAP concentration in the medium. NORTON and NORTON (1985) observed similar genotype dependent variation for shoot proliferation and plant growth regulator requirement amongst 20 cultivars of Family Ericaceae. Intraspecific variations amongst spiny and spineless genotypes of Prosopis cineraria for their shoot forming ability and phytohormone requirements were also registered (KACKAR et al., 1991; SHEKHAWAT et al., 1993). Coppicing ability of clones and their multiple bud induction capacity seems to exhibit a correlation and there by giving impetus to our belief that said traits are genetically controlled.

Multiplication rate of clones exhibited significant variations amongst themselves. Multiplication potential of these clones exhibited an erratic behavior upto six subculture cycles after which it stabilized. Therefore, multiplication experiments were carried out after six subculture cycles. Our findings are in corroboration with findings of workers where genotypic variations were encountered in the in vitro indices during culture multiplication phase (AHUJA, 1983; COLEMAN and ERNEST, 1989).

Efficiency of in vitro adventitious rooting was found to be highly variable amongst different clones. Rooting indices and auxin requirement exhibited a variation. Clones 12 and 40 exhibited higher rooting percentages as well as number. Role of 
Table 7. - Variation in root induction efficiency of microshoots of Dalbergia sissoo clones.

\begin{tabular}{|c|c|c|c|c|c|c|}
\hline \multirow{2}{*}{ Provenance } & \multirow{2}{*}{ Clone } & \multirow{2}{*}{ Parameter } & \multicolumn{4}{|c|}{ IBA } \\
\hline & & & $2.5 \mu \mathrm{M}$ & $5 \mu \mathrm{M}$ & $7.5 \mu \mathrm{M}$ & $10 \mu \mathrm{M}$ \\
\hline \multirow{9}{*}{$\begin{array}{c}\text { Pathri } \\
\text { (Uttaranchal) }\end{array}$} & \multirow{3}{*}{9} & Response (\%) & $59.72 \pm 6.36$ & $77.50 \pm 6.01$ & $70.83 \pm 4.17$ & $56.94 \pm 6.36$ \\
\hline & & Mean no. of roots & $4.93 \pm 0.51$ & $7.14 \pm 0.43$ & $6.50 \pm 0.25$ & $5.67 \pm 0.33$ \\
\hline & & Mean root length & $2.78 \pm 0.18$ & $3.34 \pm 0.44$ & $3.14 \pm 0.15$ & $2.93 \pm 0.21$ \\
\hline & \multirow{3}{*}{10} & Response (\%) & $72.22 \pm 4.33$ & $83.00 \pm 4.68$ & $68.05 \pm 6.13$ & $54.16 \pm 4.17$ \\
\hline & & Mean no. of roots & $6.28 \pm 0.75$ & $8.93 \pm 0.21$ & $6.25 \pm 0.66$ & $5.53 \pm 0.41$ \\
\hline & & Mean root length & $3.34 \pm 0.19$ & $3.49 \pm 0.05$ & $3.36 \pm 0.25$ & $2.81 \pm 0.41$ \\
\hline & \multirow{3}{*}{12} & Response (\%) & $80.55 \pm 2.41$ & $76.39 \pm 6.36$ & $61.11 \pm 2.41$ & $52.78 \pm 4.81$ \\
\hline & & Mean no. of roots & $8.26 \pm 0.96$ & $6.57 \pm 0.82$ & $5.34 \pm 0.15$ & $3.32 \pm 0.49$ \\
\hline & & Mean root length & $2.59 \pm 0.14$ & $2.52 \pm 0.54$ & $2.10 \pm 0.07$ & $1.74 \pm 0.29$ \\
\hline \multirow{9}{*}{ Gonda (U P) } & \multirow{3}{*}{36} & Response (\%) & $73.61 \pm 2.41$ & $87.50 \pm 4.17$ & $83.33 \pm 7.22$ & $78.83 \pm 4.21$ \\
\hline & & Mean no. of roots & $9.41 \pm 0.77$ & $12.12 \pm 1.63$ & $9.19 \pm 0.46$ & $8.18 \pm 0.19$ \\
\hline & & Mean root length & $4.13 \pm 0.17$ & $4.25 \pm 0.31$ & $3.92 \pm 0.17$ & $3.47 \pm 0.14$ \\
\hline & \multirow{3}{*}{40} & Response (\%) & $86.10 \pm 4.82$ & $77.11 \pm 1.82$ & $73.27 \pm 5.94$ & $70.66 \pm 4.18$ \\
\hline & & Mean no. of roots & $7.63 \pm 0.54$ & $6.63 \pm 0.57$ & $5.56 \pm 0.23$ & $5.23 \pm 0.79$ \\
\hline & & Mean root length & $3.83 \pm 0.76$ & $3.71 \pm 0.57$ & $3.25 \pm 0.10$ & $2.83 \pm 0.14$ \\
\hline & \multirow{3}{*}{44} & Response (\%) & $65.27 \pm 2.40$ & $79.16 \pm 4.17$ & $70.66 \pm 4.21$ & $67.72 \pm 2.28$ \\
\hline & & Mean no. of roots & $5.69 \pm 0.45$ & $7.11 \pm 0.49$ & $6.24 \pm 0.56$ & $6.04 \pm 0.63$ \\
\hline & & Mean root length & $3.64 \pm 0.27$ & $4.09 \pm 0.33$ & $3.48 \pm 0.27$ & $3.41 \pm 0.12$ \\
\hline \multirow{9}{*}{$\begin{array}{l}\text { Chichrauli } \\
\text { (Haryana) }\end{array}$} & \multirow{3}{*}{62} & Response (\%) & $61.11 \pm 6.37$ & $80.55 \pm 4.81$ & $75.00 \pm 4.17$ & $63.89 \pm 6.36$ \\
\hline & & Mean no. of roots & $5.09 \pm 0.67$ & $8.46 \pm 0.95$ & $6.74 \pm 0.44$ & $6.13 \pm 0.34$ \\
\hline & & Mean root length & $2.71 \pm 0.17$ & $3.11 \pm 0.12$ & $2.83 \pm 0.11$ & $2.23 \pm 0.24$ \\
\hline & \multirow{3}{*}{64} & Response (\%) & $70.83 \pm 4.17$ & $81.94 \pm 2.41$ & $62.83 \pm 4.21$ & $55.55 \pm 2.41$ \\
\hline & & Mean no. of roots & $5.62 \pm 0.65$ & $6.24 \pm 0.45$ & $4.50 \pm 0.25$ & $3.63 \pm 0.13$ \\
\hline & & Mean root length & $3.31 \pm 0.10$ & $3.51 \pm 0.17$ & $2.86 \pm 0.09$ & $2.38 \pm 0.16$ \\
\hline & \multirow{3}{*}{66} & Response (\%) & $52.78 \pm 8.67$ & $70.83 \pm 11.02$ & $76.38 \pm 8.67$ & $61.11 \pm 6.21$ \\
\hline & & Mean no. of roots & $3.93 \pm 0.59$ & $5.90 \pm 0.26$ & $5.89 \pm 0.18$ & $4.31 \pm 0.49$ \\
\hline & & Mean root length & $3.23 \pm 0.27$ & $3.63 \pm 0.36$ & $3.31 \pm 0.40$ & $2.63 \pm 0.15$ \\
\hline \multirow{9}{*}{$\begin{array}{c}\text { Hanumangarh } \\
\text { (Rajasthan) }\end{array}$} & \multirow{3}{*}{88} & Response (\%) & $58.33 \pm 7.22$ & $72.22 \pm 4.82$ & $79.16 \pm 4.17$ & $62.50 \pm 4.21$ \\
\hline & & Mean no. of roots & $3.90 \pm 0.44$ & $5.64 \pm 0.10$ & $5.82 \pm 0.26$ & $3.83 \pm 0.76$ \\
\hline & & Mean root length & $2.91 \pm 0.34$ & $3.42 \pm 0.22$ & $3.51 \pm 0.33$ & $2.28 \pm 0.06$ \\
\hline & \multirow{3}{*}{90} & Response (\%) & $52.78 \pm 4.81$ & $62.50 \pm 6.33$ & $63.33 \pm 9.61$ & $56.88 \pm 2.36$ \\
\hline & & Mean no. of roots & $4.10 \pm 0.56$ & $5.33 \pm 0.63$ & $4.36 \pm 0.38$ & $3.96 \pm 0.59$ \\
\hline & & Mean root length & $2.62 \pm 0.30$ & $2.98 \pm 0.24$ & $3.39 \pm 0.13$ & $2.31 \pm 0.22$ \\
\hline & \multirow{3}{*}{101} & Response (\%) & $47.22 \pm 2.41$ & $55.55 \pm 4.81$ & $56.94 \pm 6.36$ & $62.50 \pm 4.17$ \\
\hline & & Mean no. of roots & $3.78 \pm 0.46$ & $6.79 \pm 0.87$ & $7.07 \pm 0.41$ & $7.94 \pm 0.53$ \\
\hline & & Mean root length & $3.85 \pm 0.35$ & $3.93 \pm 0.29$ & $4.20 \pm 0.35$ & $3.32 \pm 0.52$ \\
\hline \multicolumn{2}{|c|}{ Factor } & \multicolumn{2}{|c|}{ Variable } & CD at 0.05 & F calc. & df error \\
\hline \multirow{3}{*}{\multicolumn{2}{|c|}{ Provenance }} & & & 6.54 & 14.64 & \\
\hline & & Mean no. o & oots & 1.09 & 12.74 & 140 \\
\hline & & Mean root & ngth & 0.36 & 18.14 & \\
\hline & & Response & & 17.17 & 6.24 & \\
\hline Clo & & Mean no. o & oots & 2.42 & 13.05 & 132 \\
\hline & & Mean root & ngth & 0.82 & 13.57 & \\
\hline
\end{tabular}

genotypic variations in rooting has been encountered in studies of different research groups (HoRgAN and Holland, 1989; Bergmann and Stomp, 1994; Scaltsoyiannes et al., 1994). They recorded variation in percentage of shoots rooted and number of roots per shoot.

In present study, variability has been observed in the in vitro performances of clones on the similar plant growth regulator levels as well as their plant growth regulator requirements. An interesting observation has been made during culture establishment phase that clones from one geographical unit (provenance), exhibited a remarkably similar behaviour. This suggests that these clones are derivatives of the same family and have been disseminated during their normal growth cycles. However, exception of the above is clone 12 from Uttaranchal. Superior performance of one of the clones (Clone 12) from
Table 8. - Correlation matrix between mean number of coppiced shoots and different in vitro parameters with BAP concentrations.

\begin{tabular}{cccccc}
\hline BAP & $\begin{array}{c}\text { Mean no. } \\
\text { of buds }\end{array}$ & $\begin{array}{c}\text { Response } \\
(\%)\end{array}$ & $\begin{array}{c}\text { Multiple } \\
\text { buds (\%) }\end{array}$ & $\begin{array}{c}\text { Mean no. } \\
\text { of shoots }\end{array}$ & $\begin{array}{c}\text { Buds } \\
\text { proliferated } \\
(\%)\end{array}$ \\
\hline $\mathbf{2 . 5} \boldsymbol{\mu M}$ & 0.667 & 0.727 & 0.680 & 0.596 & 0.160 \\
\hline $\mathbf{5 . 0} \boldsymbol{\mu M}$ & 0.136 & 0.545 & 0.297 & 0.065 & -0.017 \\
\hline $\mathbf{7 . 5} \boldsymbol{\mu M}$ & -0.409 & 0.091 & 0.007 & -0.526 & -0.374 \\
\hline $\mathbf{1 0} \boldsymbol{\mu M}$ & -0.004 & 0.232 & 0.177 & -0.418 & -0.424 \\
\hline $\mathbf{1 2 . 5} \boldsymbol{\mu M}$ & 0.092 & 0.155 & -0.086 & -0.539 & -0.662 \\
\hline Pooled & 0.174 & 0.346 & 0.233 & -0.11 & -0.204 \\
\hline data & & & & & \\
\hline
\end{tabular}


Uttaranchal indicates superior gene combinations or a natural variation.

Correlation matrix (Table 8) illustrated a positive significant correlation between shoot coppicing ability of clones and in vitro growth attributes of explants cultured on $2.5 \mu \mathrm{M}$ BAP except percentage conversion of buds into shoots. Result thus clearly points out that at the minimum plant growth regulator concentration in the medium in vitro attributes are strongly correlated to the plant characters in ex vitro conditions and hence are genetically governed. However, decrease in correlation with increase in BAP concentration is an indicator that different clones have different plant growth regulator requirement for their optimal performance. Correlation between shoot coppicing ability of different clones and their in vitro performances thus provides us an insight that coppicing ability of clones can be used as a parameter in media designing and adjudging plant growth regulator requirements for optimal in vitro performances. Our finding that coppicing ability is under genetic control is in concurrence with view of GURUMURTHI, (2000). In addition we suggest that in vitro traits are also genetically controlled.

Results of the present study will help the researchers in designing optimal in vitro requirements for commercial propagation of this hard wood and economically tree species, and of clones having economically important silvicultural traits. Since multiplication rate was estimated on one plant growth regulator level, hence, clones have exhibited variation in multiplication rate. However, experiments are in progress to maximize the multiplication rate of individual clones independently. It can result in increased availability of planting stock for farm forestry and production forestry purposes.

\section{Acknowledgement}

S.K. is grateful to CSIR for financial assistance for carrying out research work.

\section{References}

Ahuja, M. R. (1983): Somatic cell differentiation and rapid clonal propagation of aspen. Silvae Genetica 32: 3-4.

Bergmann, B. A. and A. M. Stomp (1994): Effect of genotype on rooting of hypocotyls and in vitro-produced shoots of Pinus radiata. Plant Cell Tissue Org. Cult. 39: 195-202.

Brown, C. L. (1981): Application of tissue culture technology to production of woody biomass. National Swedish Board for Energy Source Development. IEA Report:NE 1981-18.

Coleman, G. D. and S. G. ERNEST (1989): In vitro shoot regeneration of Populus deltoides: Effect of cytokinin and genotype. Plant Cell Rep. 8: 459-462.

ERNEST, S. G. (1993): In vitro culture of pure species non-aspen poplars. In: Micropropagation of woody plants. AHUJA, M. R. (ed.). Kluwer Academic Publishers. Pp. 195-207.

GuRumurThI, K.: Clonal forestry for tree propagation. In: Genetic Improvement and Propagation of Forest Trees. Eds. S. S. R. Bennet, K. Subramaniam, A. J. Kurian. Pb: ICFRE, India. Pp 37-61.
Haissig, B. E. and D. E. RiEmenschneider (1988): Genetic effects on adventitious rooting. In: Adventitious root formation in cuttings. Davis, T. D., Haissig, B. E. and SAnkHLA, N. (eds.). Dioscorides Press, Portland, Oregon. Pp. 47-60.

HAMmerschlaG, F. (1982): Factors affecting establishment and growth of peach shoots in vitro. Hort. Sci. 17: 85-86.

HaRtman, H. T. and D. E. Kester (1983): Plant Propagation. Principles and Practices. Prentice Hall, Inc. Englwood Cliffs, New Jersey.

HoRgan, K. and L. Holland (1989): Rooting micropropagated shoots from mature radiata pine. Can. J. For. Res. 19: $1309-1315$

Horgan, K. (1987): Pinus radiata. In: Cell and Tissue culture in Forestry. Vol. 3. Case histories: Gymnosperms, Angiosperms and Palms. BongA, J. M. and DuRZAN, D. J. (eds.) Martineuss Nijhoff Publ. Pp.: 128-145.

KACKAR, N. L., K. R. SOlanki, S. C. VyaS and M. Singh (1991): Micropropagation of Prosopis cineraria. Indian J. Exp. Biol. 29: $65-67$.

KALIA, S.: In vitro studies on morphogenesis and micropropagation of Dalbergia sissoo Roxb. and Dalbergia latifolia. PhD Thesis. Forest Research Institute, Dehradun, India. 2003.

LEAKEY, R. R. B., A. C. NewTon and J. Mc P. Dick (1994): Capture of genetic variation by vegetative propagation processes determining successes. In: LEAKEy, R. R. B. and NEWTON, A. C. (eds.). London. HMSO: pp. 72-83.

Murashige, T. and F. SKOog (1962): A revised medium for rapid growth and bioassay with tobacco tissue culture. Physiol. Plant. 15: 473-497.

NorTon, M. E. and C. R. NoRTON (1985): In vitro propagation of Ericaceae: A comparison of the activity of cytokinins $\mathrm{N}^{6}$-benzyladenine and $\mathrm{N}^{6}$-isopentyl adenine in shoot proliferation. Sci. Hort. 27: 335-340.

PAL, M., M. BAKSHI and R. PraKash (2003): Effect of coppicing height on shoot production capacity of different clones of Dalbergia sissoo Roxb. Indian Forester 504-508.

Panetsos, K. P., A. Economou and A. Scaltsoyiannes (1987): Propagation in vitro of Aspen hybrid Populus spartiatica $\mathrm{x}$ Populus tremula from mature trees. Agricultural Research 11: $449-459$

Scaltsoyiannes, A., K. P. Panetsos, A. Economou and P. Tsoulpha (1994): Micropropagation of the pine hybrid Pinus brutia (Ten.) x $P$. halepensis (Mill.) by culturing fascicle shoots. Ann. Sci. For. 51: 175-182.

Sharma, S. K. and S. Kalia (2004): Micropropagation of Eucalyptus tereticornis and interspecific hybrids. Current Advances in Plant Sciences (In Press).

Shekhawat, N. S., T. S. Rathore, R. P. Singh, N. S. Deora and S. R. RAO (1993): Factors affecting in vitro clonal propagation of Prosopis cineraria. Plant Gr. Reg. 12: 273-280.

Simpson, D. W. and J. A. BELL (1989): The response of different genotypes of Fragaria annanasa and their seedling progenies to in vitro micropropagation and the effect of varying the concentration of 6-benzylaminopurine in the proliferation medium. Plant Cell Tissue Organ Cult.17: 225-234. 